\title{
Enacting Action Learning In Art And Design Education To Create Emotional Learning Experience Amic Garfield $\mathrm{HO}^{1}$ \\ ${ }^{1}$ City University of Hong Kong, Tat Chee Avenue, Hong Kong
}

\author{
Keywords: Art and Design Education, Active Learning, Emotional Learning
}

\begin{abstract}
In art and design education, there are fundamental subjects, such as Art History, Design Management, and programme-specific subjects, such as Drawing, Typography, Printing, etc. are included. Tutors generally taught the concepts and theories of art and design through lectures followed by studio practice. This conventional teaching style was more focused on developing students' practical and theoretical skills. However, the nature of art and design education has been altered, practical and theoretical trainings were less sufficient to equip students to meet the rapidly changing trends in the art and design field. Studies in art and design education were more human-cantered and more consumer-orientated since they were influenced by technology, psychology than ever before. Therefore, students needed active learning to enrich their art and design education as well as the vibrancy of their art and design outcomes. It was found that the experience in active learning with emotional changes could be used to prompt students to actively engage in their learning activities and experience art and design concepts. Some western counties investigated the application of emotional concerns in art and design curricula. At the same time, active learning was adopted by some universities as the pedagogy of art and design subjects. Emotion would be a possible element to further enacting active learning to enrich the students to actively engage in their learning activities and experience art and design concepts. In this paper, the effectiveness of active learning and its influence on enhancing the experience and learning motivation of art and design students is examined. A case study apply emotional experience in action learning activity was conducted to provide the concrete foundation for further discussions.
\end{abstract}

\section{Introduction}

Both fundamental subjects and programme-specific subjects are included in most art and design curricula in order to comprehensively. In the conventional art and design curricula, concepts and theories of art and design was taught in lectures, and followed by studio practice. These teaching methods were believed to facilitate students' practical and theoretical skills. However, the nature of art and design changed under the influence of technology and psychology, the treads of art and design education are more human-centered and more consumer-orientated. The theoretical and skill-based training solely from art and design perspectives may were less sufficient to equip students than before. It would be difficult for students to understand the audience and consumers digest the new art and design concepts and apply them in the corresponding learning processes. Alternative methods and learning activities for art and design concepts easily were needed. United States and Russia applied of emotional concerns in art and design curricula. At the same time, active learning was adopted by some European universities as the pedagogy of art and design subjects. These teaching experiences showed that students learn more effectively if they have unforgettable learning experience and engage in reflection. Therefore, how can tutors enhance students' learning experience and motivation in art and design education? If emotions 
were crucial in facilitating education according to learning theories in psychology, tutors are possible to create emotional attachment to facilitate students' studies.

\section{The Current Landscape of Art and Design Education}

Art and design program emphasised on skill enhancement in the past. The subjects of art and design focused on the craftsmanship training in specific professional area. Typography, Photography, Illustration are the main subjects to help art and design students develop their skills in specific profession in the art and design fields. The basic subjects such as Art History and Design Thinking were developed particularly to provide students' knowledge on concept and skills development in art and design field. Art and design program in recent decades focused on the work of art and design in communication and problem solutions. The knowledge like branding, advertising and media art, etc. delivered to teach the art and design students the methods of expressing their concerns through art pieces as well as the appropriated solutions on design problems. Creative thinking and Skills in Problem Solving encouraged students to consider design from the ethical result-centred perspective. However, influenced by technologies, psychologies and business than ever before, the art and design field will be more human-cantered and more consumer-orientated. Moreover, there are needs for services and processes that do not required the great craft skills that the emphasised as the primary outcomes of a design education in the current climate. In the foreseeable future, art and design would be shifted to be experience emphasised or user-centred focused. These experience emphasised and user-centred focuses referred to the focus on the goals those aimed to satisfy the needs, wants, and limitations of the end user of the designed artifact. Some inter-disciplines subjects were included in the professional specific subjects, such as Interface Design, Information design, Innovation Tools for Strategic Design, User Oriented Design, Experimental Typography, Photo Art Direction, Information Architecture and Visualization, Collaborative Design and Technology, Skill in design research and project management. Art and design becomes a kind of media to facilitate experience or user instruction.

\section{Students' Emotions and Learning}

Following the above investigation, this direction revealed the importance of audience /users' needs and preferences in the art and design process. Artists and designers understood and created experience that encouraged users responding through their emotions, motivations and beliefs to the design through user observations, one-on-one interviews, etc. By understanding the human's response to the external environment, artist and designers could generate art pieces and design outcomes could accommodate users' behaviors naturally. Hence, students needed the guidance enabling them to participate, ensuring that the questions build up coherently and checking that participants reflect on each step of the art and design process. Tutors were important to lead students achieve their learning goals through experience and reflection but not the ready-made solutions. Some art and design scholars proposed active learning should be adopted as one of the art and design pedagogy. [1,2] Action learning proposed that students learned from the experience of dealing actual situation and reflection on their actions.[3] After tackling issues (the process), students gain experience (including knowledge and emotions) and then summarise their experience in their reflections, hence students can use their reflections to tackle other issues. Under action learning, students acquired knowledge through reflecting on actual actions and practices rather than traditional instructions. Reflection was the fundamental of action learning process. 
It was mostly done in conjunction with others in small groups. Each student was encouraged to review and reflect every step in the learning process. The reflections guided the future actions of students and improve their skills in the follow learning process. Action learning also offered a framework that can be applied to research experience and case study development. This approach particularly suited to the context of art and design education. [4] Action learning helped art and design students in graduated level to prepare for creative and management careers. They were the tools for instilling self-confidence and facilitating professional development.

\section{Emotional Concerns in Action Learning}

Some countries, for example, United States,[5]Russia [6] proposed emotion was an important aspect of their educational curricula. Tutors in United States looked for an effective educational model to achieve better academic outcomes. Tutors suggested that the aim of education is not only to provide academic training, but also to endow students with the ability for contributing the society.[7] They placed a great deal of emphasis on the feelings, beliefs, attitudes and emotions of students and tried to include these psychological phenomena in the educational process. At the similar time, the Psychology for Adolescents course in Russian schools, students explored skills of problem solving and creativity as part of basic psychological programmes in primary and secondary schools. The programme examined different kinds of creative activities and presented creativity as the production of ideas that influence the environment. The formation of a subjective creativity was demonstrated through the activities for training students in communication skills. These tailor-made creative processes were taught according to the specific aptitude of each student. As a result, students acquired skills in controlling their own emotional states and making decisions about the future. Students learned to appreciate their own capabilities and those of their peers and were encouraged to create artworks that satisfied their personal expressive needs. Students learned and recognized art and design as a means of self-expression and creativity. In the process, they acquired a clearer sense of themselves, discovered new and more varied ways of communication, and developed a better understanding of human interaction and relations. They were also able to connect their classroom experiences with the wider social and cultural environment. In all, emotional education had been found to develop creativity and enhance students' ability to make decisions. Learned from these general educations, emotion was not only a factor those influencing students' daily lives. It was a knowledge that actually influences students' various learning abilities. In order to enhance students' learning ability, the methods of manipulating emotion, emotional literacy and some other topics were developed as subjects in some western countries. It was found that emotion would be applied at other subjects, no matter from primary studies or the levels above mentioned. These training of emotion would help students to understand themselves and appreciate their own works. This would help students learn to understand themselves, appreciate their own abilities, get along with their peers, and encourage them to work in a creative and appreciate manners. It was a very good opportunity for tutors to understand the importance of emotion to education.

\section{Action Learning with Emotional Concern in Art and Design Education}

Based on the experience in emotional education, emotion helped students to recall their learning process. While art and design students manipulate their art and design processes (i.e. experience) and then record their art and design processes for reflection 
(including their emotional changes and the actions they took) under the concepts of action learning, emotional changes enhanced their understanding on the art and design concept and art and design process. The emotional changes in the learning process encouraged self-expression and creativity. After reflecting on their art and design processes, students recalled how they felt after a similar event in the past (i.e. reflection) and then determine actions they need to take. This reflection would help students to understand their various emotional states, strengths and weaknesses of particular emotion, and thereby raise their emotional awareness. In other words, action learning provided a dialogue that let to focus on what they experienced in their learning process. Emotion was suggested to be the supplement of the action learning in management learning. [8] Psychological and political processes (i.e. emotional and rational factors) took place inside action learning to cause personal changes. The experience in action learning process such as practices, work in real situations, individual reflections, etc. were affected the individual's desire (emotion) and determine whether he or she wishes to continue the learning process. Individuals who had strong motivation to continue the process would have stronger ability to overcome difficulties and continue the process. Emotion therefore indeed involved in and even drove the development of learning process. Compare to other learning methods, action learning enabled students to experience the art and design process, to be aware of and obtain information on their emotional changes, and understand the influence of emotion on their decision making and actions. Students were able to handle different art and design projects, starting the cycle again, experiencing and learning more. [9]

\section{Case Study of Applying Emotion with Active Learning in Art and Design: Types Classification}

A year one art and design course: Typographic Design was selected as the case study to examine how emotion would improve active learning in art and design education. Types Classification was an importance topic, in the conventional Typographic Design course. Tutors delivered the guideline of Types Classification informatively for the class. The main categories of types: Black letter, Old Style, Script, Transitional Style, Modern Style, Slab Serif Style, Sans Serif Style were introduced. However, it was generally found that students had difficulties to remember all the features and characteristics. Some of the students felt confused to identify the difference between the categories. At the same time, Types Classification was not regarded as an important one by the students. Few students consumed time to investigate more for this topic and recognized it was indeed a fundamental topic in typographic. Students should understand Type Classification well in order to know the proper way to use the different types. In this case study, two different approaches of the teaching Type Classification were compared. 2 classes of undergraduate students, 20 students were arranged in each class. One adopted the Conventional teaching methods of Type Classification (solely provided theoretical understanding in a lecture); and the other one adopted the emotional action learning (the students obtain a lecture on theoretical understanding and took part in a Type Classification learning experience: "Finding Friends"). In this "Finding Friends" learning experience, every student had been assigned an A4 paper one font name and whole set of font printed on. They had to found their 'friends' among the class. Students could not directly ask the font name or the corresponding category when finding their friends. They could only ask about the features of each other's font like serif or san serif, oblique stress or vertical stress, etc. and hence determine if he/she should be paired up as friends. Eventually, the group 
used the shortest time to pair up under the same category in type classification would be the winner. Students' performances were observed. (Refer with: Table 1) Indeed, through the lecture in both two classes, the knowledge of the Types Classification was provided. In lectures, background information, features were presented in the same way. To understand the actual influence of action learning with emotion on the learning process, a test on the knowledge of the Types Classification was conducted after the class. Compare to the conventional class, the class adopted the emotional action learning were more excited with the learning process. The students were very excited. They followed instructions to finish the task in with a happy feeling. The activities would be held for three to four times in order to let students understand how to identify different types in classification. They quickly remembered all these categories with its backgrounds and features through this learning activity. In the test of Types Classification, the average scores of the students from the emotional action learning was 83. It was much higher than one under the conventional teaching that was 55 . (Refer with: Table 2)

Table 1. Table shown the different approaches of the teaching methods adopted in the Conventional and modified courses of type classification.

\begin{tabular}{|l|l|l|}
\hline & $\begin{array}{l}\text { Conventional Type } \\
\text { Classification Teaching }\end{array}$ & $\begin{array}{l}\text { Emotional Action Learning } \\
\text { Experience on Type }\end{array}$ \\
\hline The Leading Role & Teacher-oriented & Student-oriented \\
\hline Main Learning Mode & Learning from literatures & $\begin{array}{l}\text { Learning form experience } \\
\text { and interactions in the class, } \\
\text { reflections after the class }\end{array}$ \\
\hline $\begin{array}{l}\text { Emotions Identified by } \\
\text { The Participants }\end{array}$ & Frustrated, boring & Interesting, exciting \\
\hline
\end{tabular}

Table 2. Table shown the average scores of the students obtained in the a test on the knowledge of the Types Classification

\begin{tabular}{|l|l|l|}
\hline & $\begin{array}{l}\text { Conventional Type } \\
\text { Classification Teaching }\end{array}$ & $\begin{array}{l}\text { Emotional Action Learning } \\
\text { Experience on Type }\end{array}$ \\
\hline $\begin{array}{l}\text { Average Scores of The } \\
\text { Students }\end{array}$ & 55 & 83 \\
\hline
\end{tabular}

\section{Conclusion}

In order to train art and design student comprehensively, some tutors believed that students needed both practical and theoretical training. However, influenced by the changes of nature in art and designs, the actual art and design process included more unpredicted situations or elements those might influenced the art and design process and the art and design outcomes. This caused more difficulties to art and design students when they try to apply the new learning art and design concepts in the learning process. Alternative methods for helping students to understand the art and design concepts in some specific learning activities are needed. At the same time, some of the studies in art and art and design education investigated that students would be more capabilities if they had emotional experience in the art and design education process. In the case study of learning about typographic categories, students felt difficult to identify the features and categories of typographic. Different Western curricula and learning programmes concerned students' emotion in their learning experiences and reflections on real situations. These learning experiences made them more sensitive to their emotional changes. As this learning process focused on experience and reflection, it was similar to the action learning approach. In this preliminary study, action learning 
was proved to be a potential learning method for introducing emotion into the art and design curricula. Further investigation on actually introducing emotion into action learning in art and design studies was needed.

\section{References}

[1] Moore, A.H., Fowler, S.B., Waston, C.E., Active learning and technology: designing Changes for faculty, students, and institutions, Addison-Wesley, Reading, 2007.

[2] Watson, E.C, Self-Efficacy, the Innovation Decision Process, and Faculty in Higher Education: Implications for Faculty Development, Virginia Polytechnic Institute and State University, 2007.

[3] Weinstein,K., Action learning, Gower Publishing Ltd., London, 1998.

[4] Chattaraman, V., Sankar, C., \&Vallone, A., Action learning: Application to case-study development in graduate design ed. Art, Design \& Communication in Higher Education, 9(2), 183-198, 2010.

[5] Adams, J. E., Education reform, in J. W. Guthrie (Ed.), Encyclopedia of education (pp. 512-515), Macmillan Reference USA, New York, 2003.

[6] Zabrondin,Y., Popova, M. \&Minaev, A., Affective education: A Russian perspective, in Y. J. Katz, P. Lang, \& I. Menezes (Eds.), Affective education: A comparative view (pp. 46-57), Cassel, London, 1998.

[7] Camus, A., The first man, Knopf, New York, 1996.

[8] Vince, R. \& Martin, L., Inside action learning: An exploration of the psychology and politics of the Action Learning Model. Management Education \& Development, 24 (3), pp.205-215, 1993.

[9] Anderson, G., J., Clarke, L., J. and Thorpe, R., To act and learn: a Bakhtinian exploration of action learning. Action Learning: Research and Practice. 6 (2), pp. 121-130, 2009. 